\title{
Effect of Head Rotation on Jugular Vein Patency Under General Anesthesia
}

\author{
Mark A. Burbridge (D), Jung Gi Min, Richard A. Jaffe
}

\begin{abstract}
Head rotation causes compression and occlusion of the ipsilateral internal jugular (IJ) vein. This can result in raised intracranial pressure and increased bleeding if the patient is having or has recently had surgery. The amount of head rotation in adults resulting in occlusion of the ipsilateral IJ vein is unknown however. We measured the amount of head turn that produced occlusion of the ipsilateral IJ vein in 25 patients having surgery under general anesthesia. On average, $80 \%$ of IJ veins occlude at a mean of $55.6^{\circ}$ on the left and $53.3^{\circ}$ on the right.
\end{abstract}

RÉSUMÉ: Les effets de la rotation de la tête sur la perméabilité de la veine jugulaire en cas d'anesthésie générale. Des rotations de la tête peuvent entraîner une compression et une occlusion de la veine jugulaire interne ipsilatérale. Cela peut en retour provoquer une pression intracrânienne accrue et une augmentation des saignements si le patient est en train de subir une chirurgie ou s'il en a récemment subi une. Le degré de rotation de la tête qui entraine une occlusion de la veine jugulaire interne ipsilatérale demeure toutefois inconnu. Nous avons mesuré chez 25 patients sous anesthésie générale le degré de rotation de la tête ayant produit une telle occlusion. En gros, $80 \%$ des veines jugulaires se sont en moyenne obstruées à 55,6 degrés à gauche et à 53,3 degrés à droite.

Keywords: Anesthesia, Critical care, Intensive care, Ischemic brain injury, Neurointensivist, Neurocritical care, Neurological examination, Neurosciences, Neurosurgery, Neurotrauma

doi:10.1017/cjn.2019.13

Can J Neurol Sci. 2019; 46: 355-357

Radiographic and clinical studies on primates ${ }^{1}$ and children ${ }^{2,3}$ have demonstrated that rotating the head laterally to the right or left results in compression of the ipsilateral internal jugular (IJ) vein, most prominently in the middle third of the course of the vein. Furthermore, direct intracranial pressure (ICP) measurements from external ventricular drains in critically ill patients in the intensive care unit have demonstrated in adults ${ }^{4,5}$ and neonates ${ }^{6}$ that head turning causes significant increases in ICP that persist for the duration that the head is turned and the patient remains supine. Presumably, lateral rotation of the head results in obstruction of venous drainage, causing intracranial venous congestion, and increases the risk of bleeding. This is particularly relevant to the care of patients undergoing craniotomy where the head is often positioned with significant lateral rotation to obtain optimal surgical exposure. The effect of head rotation on ICP is eliminated when the patient is repositioned from supine to $30^{\circ}$ of head elevation. ${ }^{7}$

While these previous studies demonstrate that head rotation can cause ipsilateral IJ compression and ICP elevation, there are no measurements of the angle at which the IJ vein occludes in adults. Such knowledge would allow anesthesiologists and surgeons to more optimally position patients undergoing neurosurgical procedures where intraoperative blood loss was a concern. In this study, we measured the effect of head rotation on IJ vein patency in 25 adult patients using ultrasound imaging with color Doppler to determine the angle at which the ipsilateral IJ vein occludes in adults under general anesthesia.

This research study was approved by the university Institutional Review Board (IRB \# 17779, approved on 12-19-2017).

Patients were approached in the pre-operative area and those who agreed to participate signed a consent form and were included in this study. Patients were then brought to the operating room (OR) and anesthesia was induced with medications and dosages at the discretion of the attending anesthesiologist. All patients received an intubating dose of rocuronium $\geq 0.6 \mathrm{mg} / \mathrm{kg}$. They were then positioned on the operating table in the supine position, with the OR table leveled, on a head cradle (DeRoyal, Powell, TN, USA). All patients were intubated with a size 7.0 endotracheal tube (Covidien, Mansfield, MA). They were then placed on the ventilator on a Drager Apollo anesthesia workstation in volume control ventilation mode, with tidal volume of $6 \mathrm{~mL} / \mathrm{kg}$ and positive endexpiratory pressure of $5 \mathrm{~cm} \mathrm{H}$ within $20 \%$ of baseline during this period with boluses of ephedrine or phenylephrine as determined by the attending anesthesiologist. All ultrasound measurements were taken by one of the authors (MB) for consistency, after the induction of general anesthesia prior to starting the surgical procedure and after the administration of less than $250 \mathrm{~mL}$ of intravenous crystalloid fluid. Operating table belts, straps, and any other sources of extraneous abdominal pressure were ensured to be absent. An ultrasound machine (FujiFilm Sonosite, Bothell, WA, USA) with a 6-13 MHz bandwidth probe was then applied over the IJ vein with careful attention paid to apply only the minimal amount of

From the Department of Anesthesiology, Perioperative and Pain Medicine, Stanford University School of Medicine, Stanford, CA, USA (MAB, RAJ); Stanford University School of Medicine, Stanford, CA, USA (JGM)

Received July 6, 2018. Final Revisions Submitted December 7, 2018. Date of AcCePtance January 27, 2019.

Correspondence to: Mark A. Burbridge, Department of Anesthesiology, Perioperative and Pain Medicine, Stanford University School of Medicine, 300 Pasteur Drive Palo Alto, Stanford, CA 94304, USA. Email: markburb@stanford.edu 


\section{Table 1: Surgical procedures patients underwent}

\begin{tabular}{l|c}
\hline Surgical procedure & Number of patients \\
\hline Lumbar spine microdiscectomy & 5 \\
\hline Internal pulse generator insertion & 3 \\
\hline Craniotomy for depth electrode insertion & 4 \\
\hline Knee arthroplasty & 4 \\
\hline Spinal cord stimulator insertion & 2 \\
\hline Craniotomy for brain tumor & 1 \\
\hline Umbilical hernia repair & 3 \\
\hline
\end{tabular}

pressure needed to obtain a satisfactory image, with a depth on the monitor of either 2.6 or $3.1 \mathrm{~cm}$ depending on the depth of the IJ in each patient, at the level of the cricothyroid membrane consistent with the middle third of the course of the IJ. Measurements were taken during both inspiration and expiration and the occlusion angle was determined when the vessel first occluded. A digital angle gauge (Wixey, Santa Clara, CA, USA) was then placed on the patient's forehead and zeroed in the neutral position. Head rotation was slowly commenced and ceased when the occlusion of the ipsilateral IJ vein was confirmed with a lack of flow on color Doppler. The degree to head rotation on the digital angle gauge was recorded. Patency of the contralateral IJ vein was also assessed at this time. This process was repeated on the contralateral IJ vein.

Twenty-five patients (15 male and 10 female) were studied. Inclusion criteria included any patient requiring general anesthesia and presenting for any surgical procedure except those of the head/neck and thorax. Surgical procedures are shown in Table 1. All patients followed standard fasting recommendations and clear fluids were encouraged up to 2 hours prior to surgery consistent with an institutional protocol. Exclusion criteria included previous surgery, radiation, or central line placement due to potential anatomical distortion and/or scarring, and any pathology that could result in significant fluid shifts or cardiorespiratory disease that could alter venous drainage into the right atrium (such as tricuspid stenosis). Patient demographic information included an average age of 52.8 years, average weight of $82.4 \mathrm{~kg}$, average body mass index of 28.9 , and average height of $171.2 \mathrm{~cm}$. On a left head turn, 21/25 (84\%) IJ veins occluded at an average head turn of $55.6^{\circ}$ (range, 38.4-72.5). On a right head turn, 19/25 (76\%) IJ veins occluded at an average head turn of $53.3^{\circ}$ (range, 36.3-62.4). Of those that did not occlude, 4 patients did not occlude their IJ vein on both sides (patients 6, 12, 13, and 14), and 2 patients did not occlude their right IJ but did occlude their left IJ (patients 8 and 24). These data are shown in Figure 1. Figure 2 demonstrates representative ultrasound images obtained during this study. All patients demonstrated a patent contralateral IJ vein when occlusion or maximal neck rotation was established.

This is the first study to quantify the angle of head rotation that occludes the IJ vein in adult patients under general anesthesia. These data are particularly useful in the perioperative and critical care of patients with intracranial pathology. In the OR, it is useful because in procedures where blood loss is of concern, modifications can be made to reduce venous congestion if a head turn is required for surgical positioning, such as reducing the degree of head rotation, or elevating the head of the OR table to $30^{\circ}$ or more, which has been shown to decrease venous congestion and ICP even when the head is turned but would increase the risk of venous air embolism during neurosurgical procedures. In the intensive care unit or wards, it is useful for patients who may require some degree of head rotation for therapeutic interventions such as external ventricular drain placement or dressing changes. For the post-operative neurosurgical patient, decreasing venous pressure in the brain can lead to a decreased risk of post-operative

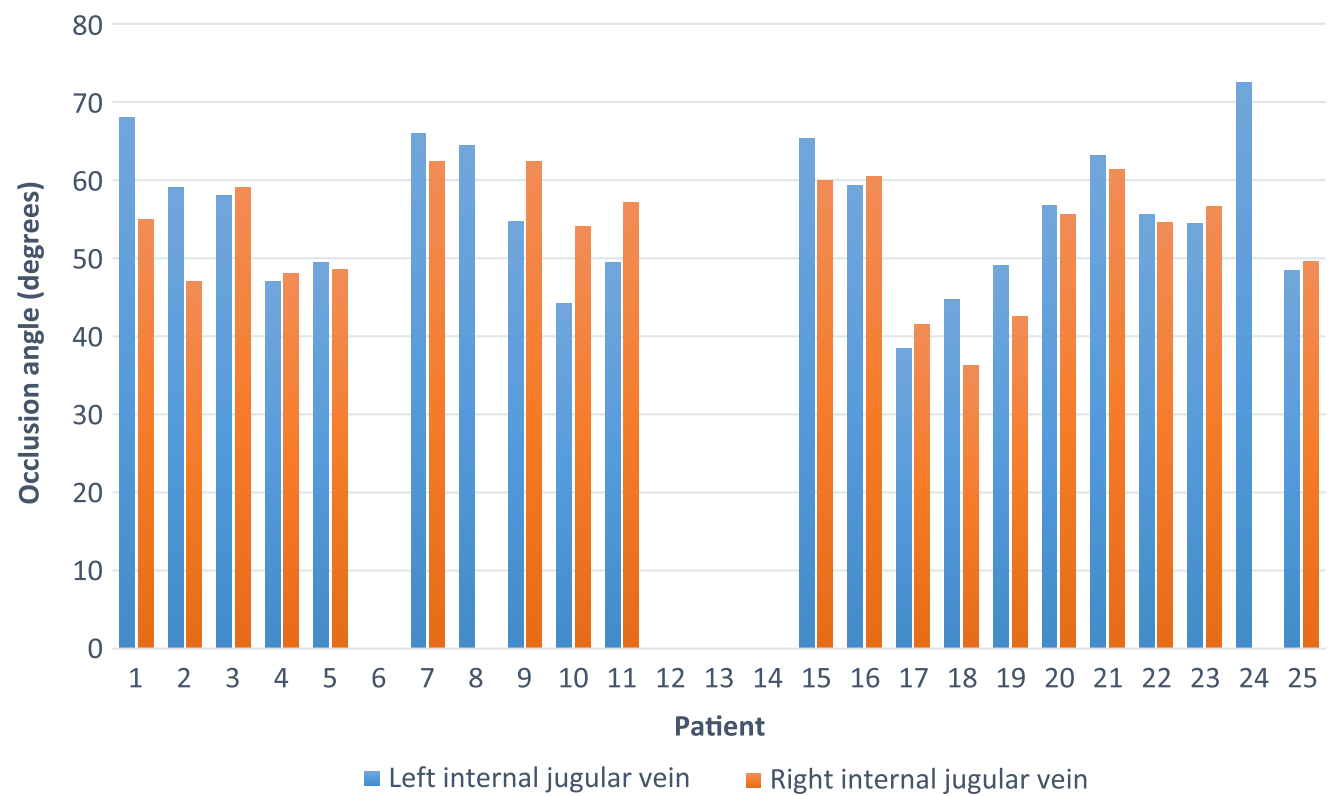

Figure 1: Occlusion angle of right and left IJ vein by patient. Patients without data did not occlude the respective IJ with maximal head rotation. 
A

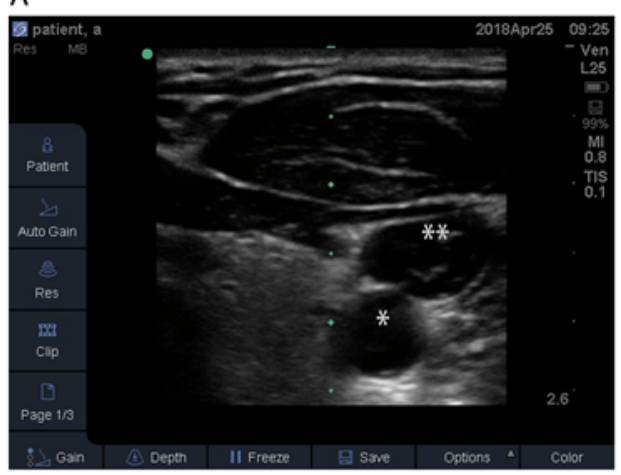

B

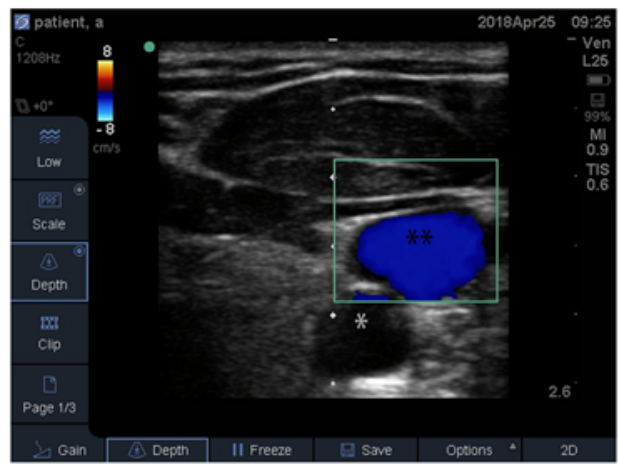

C

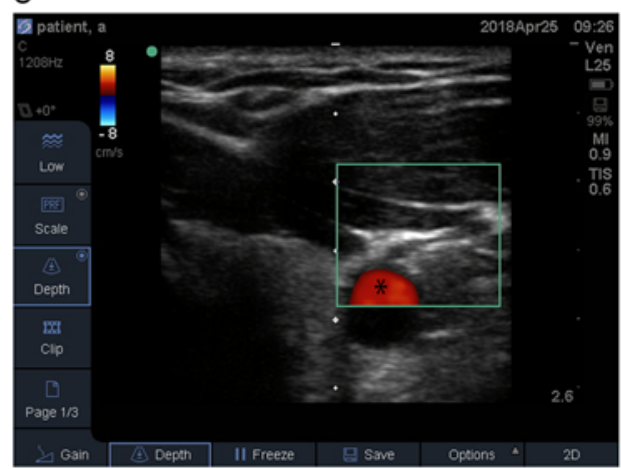

Figure 2: Ultrasound images of the left neck showing (A) without color Doppler, the common carotid artery $(*)$ and $\mathrm{IJ}$ vein $(* *),(B)$ the common carotid artery $(*)$ and IJ vein $(* *)$ with color Doppler, and $(C)$ the common carotid artery $(*)$ and compressed $\mathrm{IJ}$ vein at $53^{\circ}$ of left neck rotation.

bleeding from delicate resection cavities or vascular anastomoses and decreased ICP from decreased vascular engorgement.

In conclusion, we demonstrate for the first time, using ultrasound color Doppler imaging, that an adult being mechanically ventilated under general anesthesia will occlude their left IJ at an average of $55.6^{\circ}$ and their right $\mathrm{IJ}$ at an average of $53.3^{\circ}$. We also show that not all patients will occlude their ipsilateral IJ with maximal head turn. Although not directly measured in this trial, ICP would be expected to increase substantially when the IJ is occluded based on previous research findings. This information will aid anesthesiologists and neurosurgeons to optimally position patients during surgery, especially during procedures where the potential for blood loss is a concern, and also for critical care physicians and neurologists to more effectively manage such patients.

\section{Conflicts of InTEREST}

The authors have no conflicts of interest to declare.

\section{REFERENCES}

1. Gooding CA, Stimac GK. Jugular vein obstruction caused by turning of the head. Am J Roentgenol. 1984;142(2):403-06.

2. Gwak MJ, Park JY, Suk EH, Kim DH. Effects of head rotation on the right internal jugular vein in infants and children. Anaesthesia. 2010;65:272-76.

3. Watson GH. Effect of head rotation on jugular vein flow. Arch Dis Child. 1974;49(3):237-39.

4. Williams A, Coyne SM. Effects of neck position on intracranial pressure. Am J Crit Care. 1993;2(1):68-71.

5. Mavrocordatos P, Bissonnette B, Ravussin P. Effects of neck position and head elevation on intracranial pressure in anaesthetized neurosurgical patients: preliminary results. J Neurosurg Anesthesiol. 2000;21(1):10-14.

6. Goldberg RN, Joshi A, Moscoso P, Castillo T. The effect of head position on intracranial pressure in the neonate. Crit Care Med. 1983;11(6):428-30.

7. Hung OR, Hare GMT, Brien S. Head elevation reduces head-rotation associated increased ICP in patients with intracranial tumours. Can J Anaesth. 2000;47(5):415-20. 